clearly address a conservation issue of international importance, and should preferably be derived from the priorities identified by ICBP, IUCN, or similar organizations - for example, focusing on species that are listed in the Red Data Books. Each expedition should involve local students or counterparts, and must have clearance from the host government.

The hope is to have each year four prizes in two categories: (a) Birds ( $£ 1,000$ and $£ 800$ ), and (b) all other wild animals or plants $(£ 1,000$ and $£ 800$ ). The category of 'Highly Commended' will be awarded to expeditions that are not winners but are considered of high organizational merit and conservational potentiality. Clearly the prize will only cover a proportion of the total cost of an expedition; but it is anticipated that any project in receipt of this prize or an 'endorsement', will be able to present a strong case for further funding from national or international grantawarding bodies. The closing date for entries each year is 31 January and the results will be announced on 31 March.

Although many expeditions may have missed the deadline for this year's competition, we hope that those whose activators are starting to think about projects for 1990 will consider applying. The guide for applicants provides advice on the type of project to consider, how to submit applications for funding, and reference sources. Successful applicants are sent a guide to preparing the final report of their expeditions. The Royal Geographical Society attributes the vast increase in top-quality ornithological expeditions to the guidelines issued for the ICBP award, and welcomes the expansion of the competition. For further information please contact either ICBP, 32 Cambridge Road, Girton, Cambridge CB3 0PJ, England, UK, or FFPS, 79-83 North Street, Brighton, East Sussex BN1 1ZA, England, UK.

\section{SuSAN M. Wells \\ Assistant Director (Information)}

International Council for Bird Preservation 32 Cambridge Road Girton

Cambridge CB3 OPJ

England, UK.

\title{
BTCV for Practical Action in Conservation
}

Britain has a long history of voluntary involvement in Nature conservation, which has become enshrined in a firm partnership between governmental and non-governmental agencies. The British Trust for Conservation Volunteers (BTCV) is the United Kingdom's largest organization involving volunteers in such practical work. The particular philosophy behind this organization stems from an urge to put something back into the countryside, through practical work, and this has, over BTVC's 30years'-history, been turned into a successful recipe for introducing young people to Nature conservation.

This approach of putting something back has appealed to other countries. Thus staff at the Icelandic counterpart of the British Nature Conservancy Council were familiar with the work of BTCV and shared the philosophy that conservation volunteering is more than just a means of getting things done when money is in short supply. Environmental education through practical involvement was accordingly adopted to try and arouse a new feeling of understanding and care for the very sensitive Icelandic environment. To this end a group of staff and volunteers from BTCV were invited to Iceland in 1983, with the objectives of helping to initiate some practical projects and explaining their organization's structure and activities in Britain. Since then an expedition to Iceland has become an annual feature of BTCV's summer programme.

In 1984 an ambitious two-months' project was undertaken in Iceland's Skaftafell National Park, continuing the work done in the previous year. Over an 8 weeks' period, a total of $520 \mathrm{~m}$ of $c .15-\mathrm{cm}$-wide permeable drainpipe was fitted, 18 culverts were built, and 15 stone steps and 1,100 $\mathrm{m}$ of path were constructed or reconstructed. Many Icelandic volunteers turned up for their first experience of practical conservation work, and since then smaller groups of British volunteers have worked with the Icelandic group which is now independant of their Nature Conservancy Council and, being run by volunteers, is going from strength to strength (Fig. 1).

BTCV is now taking these experiences further, having put forward a resolution at the IUCN 16th General Assembly that personal practical involvement in conservation projects is an important way of implementing the philos-

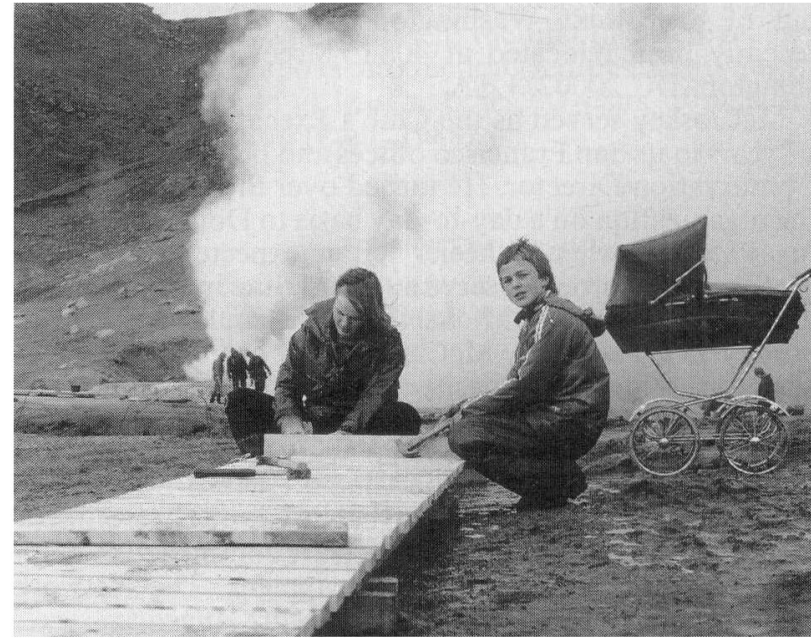

FIG. 1. Volunteers in Skafiafell National Park, Iceland, building a board-walk-their first experience of volunteering.

ophy of the World Conservation Strategy. Moreover, BTCV is taking the lead in seeking international cooperation for training and development of the necessary skills pertaining to such work.

In 1988 and 1989 , BTCV is developing a network of groups and organizations involved in volunteering for conservation good-works in much the same way as they did in Iceland, helping to purvey the philosophy and spirit of volunteering along with practical help in skills of leadership and motivating volunteers. BTCV is looking for partners in further countries, and would be willing to help anybody who wishes to develop a volunteer group. For information please contact the undersigned:

Anita Prosser, International Development Officer British Trust for Conservation Volunteers (BTCV) 36 St Mary's Street

Wallingford

Oxfordshire $O X 10 \mathrm{OEU}$

England, $U K$. 